\title{
Solar Refrigerator For Vaccines In Rural Areas
}

\author{
Dr.V.V.Karthikeyan ${ }^{1}$, L.Kalaivani ${ }^{2}$, L.Naveena ${ }^{3}$, B.Nivetha ${ }^{4}$ \\ ${ }^{I}$ Professor, Department of Electronics and Communication Engineering, SNS College Of Engineering, \\ Coimbatore \\ ${ }^{2}$ Student, Department of Electronics and Communication Engineering, SNS College Of Engineering, \\ Coimbatore \\ ${ }^{3}$ Student, Department of Electronics and Communication Engineering, SNS College Of Engineering, \\ Coimbatore \\ ${ }^{4}$ Student, Department of Electronics and Communication Engineering, SNS College Of Engineering, \\ Coimbatore
}

\begin{abstract}
Solar energy based temperature controlled chamber is presented in this paper. This technique is primarily concentrated in the medical arena.Using the Peltier module the temperature controlled chamber is utilized for the dual purposes i.e. cooling and warming. As the temperature controlled chamber is compact and easy to carry the vaccines to rural regions, it is mainly designed.This organization concentrates on solar energy in order to avert the environmental contamination. The existing system outlines the implementation of cooling and heating in an exclusive unit.The conflict between the existing and projected system is, both chilling and heating takes place in the individual unit.
\end{abstract}

Keywords: - Solar panel, Peltier module, Single chamber.

\section{INTRODUCTION}

This system consists of Embedded devices, Solar panel, Charger, Battery, Display,Analog to Digital Converter (ADC), Temperature sensor, Driver, Peltier Module, Temperature controlled chamber and Keypad. The solar panel is applied to convert the heat energy into electrical energy and it is fed to the charger, which is checked by the implanted system and the output of the charger is given to Battery to store the electric potential. Again the Battery voltage is given to the ADC, the ADC is used to measure the Battery voltage and converts it into a digital signal and given back to embedded system. When the level of the voltage decreased below a threshold value $(<11 \mathrm{~V})$, the charger is activated and solar voltage is given to a battery for storage. The temperature sensor is used to measure the temperature of the chamber and the output of the temperature sensor is given to $\mathrm{ADC}$, where $\mathrm{ADC}$ converts analog signal to digital signal and given to Embedded system. The Embedded system is programmed like that when it receives the signal from the keypad it checks the temperature of the chamber and activates the Driver. The driver is used to run the Peltier module. Peltier is a Module which generatesa voltage when there is a differenttemperature on each side. Conversely, when a voltage is applied to it, it creates a temperature difference. At the atomic scale, an applied temperature gradient causes charge carriers in the material to diffuse from the hot side to the cold side. So the Peltier module can cool and heat the chamber. The keypad is used to set the temperature value to the chamber and at the same time the display used in this system to show the process carried out in the system. The following Figure 1 shows the overall system block diagram of the solar refrigerator for vaccine.

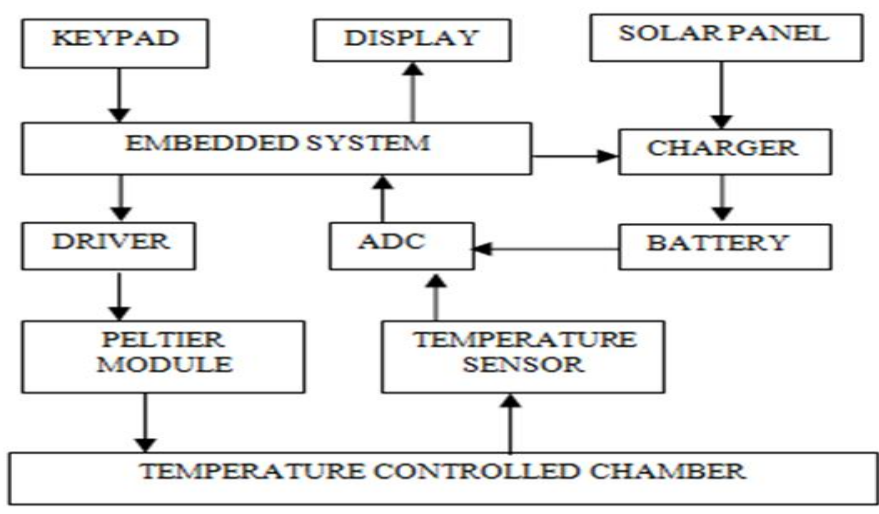

Figure.1 Overall system block diagram 


\section{LITERATURE REVIEW}

The prototype 40- liter solar refrigerator was designed and developed for monitoring its performance in Indian climate and evaluates the economic feasibility and affordability in domestic, commercial and industrial applications. In this method, this prototype solar refrigeration system, refrigerator used the photovoltaic power for performing its operations. This system was designed with battery storage for enhancing the performance of the refrigerator. The refrigerator consists of 48-watt, AC compressor. In this prototype the following factors are concentrated. The natural convection heat transfer mode was considered. The refrigerator cabinet had been divided into vertical and horizontal surfaces. Pressure variations in the direction perpendicular to the plate are neglected. The viscous forces were assumed to be negligible. The radiation heat transfer to the cabinet is negligible. In addition to this in this method (Sanjaykumar A et al., 2008) for analyzing the cooling load and for mathematical modelling of the refrigerator, the method of boundary layer analysis for natural convection was used.

The photovoltaic driven refrigerator cum heating system powered from solar panels with a battery bank was implemented by Surith Nivas. M (2013). This was different from conventional refrigeration systems, thermo-electric refrigeration. It was mainly based on the Peltier effect and it does not require any compressor, expansion valves, absorbers, condensers or solution pumps. In this system electrons were used as a heat carrier instead of the refrigerants. They have made a new refrigeration cum heating utilizing 3 thermo-electric (Te) modules mounted around a load cabinet. The performance of this method was evaluated with an aluminium cabinet. The cabinet attained a temperature of about $8^{\circ} \mathrm{c}(\mathrm{min})$ till $200^{\circ} \mathrm{c}(\max )$. It was observed in this experiment that the life span of thermo-electric heater cum refrigeration was more than twice the life span of existing conventional refrigeration (or) heater system.

S. Haidar et al. described the conversion of thermal energy into electrical energy (Seebeck effect) or electrical energy into thermal energy (Peltier effect) takes place with the help of thermo-electric devices. The electromotive force was generated when heating between two dissimilar metals takes place. In this the reverse operation was also possible. The transformation of heat from one side to another side was made possible by passing electric current with the development of semiconductors. In this two Peltier cells were used as a heat pump. That was used for cooling the small refrigerator, CPU coolers, and electronic component.

\section{EXISTING SYSTEM}

In recent years the price ofthermoplastic materials is declining, so the cost ofsemiconductor, solarrefrigeration production will decrease, andits performance has improved, which greatly contribute to thepromotion of the technology of solar semiconductorrefrigeration. Now there are many mature technologymethods for the use of solar energy for refrigeration. However,no matter the absorption of solar energy, or steam jet, etc., All ofthem need to use fluoride, lithium bromide and ammoniarefrigerants. In contrast, semiconductor refrigeration has moreobvious advantages. It does not use refrigerants withoutenvironment pollution and complicated transmission pipeline.It can only cool a special device or a specific area. The coolingbox has small size and light weight, and it can save theconstruction area significantly. No mechanical rotation, so thecooling box is reliable and the maintenance was easy withoutnoise and wear. It can achieve the two different purposes ofcooling and heating by changing the direction of current. The cooling was quick and it can be controlled by regulating the workof power, so the control is very convenient. In this case, theproduct was designed by combining the two advantages. The system includes solar cells, controllers, batteries, semiconductor refrigeration part, and so on.Since solar energy is not continuous, in order to ensure thatthe refrigerator can be worked continuously at night and cloudy days, generally the system was equipped with a battery (battery is also playing the role of the regulator in this system) and it was alsoequipped with a controller which has the function of protectingbattery to avoid over charge and over discharge.

\section{PROPOSED SYSTEM}

Solar panels are comprised of several individual solar cells. These solar cells function similarly to large semiconductors and utilize a large-area p-n junction diode. When the solar cells are exposed to sunlight, the p-n junction diodes convert the energy from sunlight into usable electrical energy. The energy generated from photons striking the surface of the solar panel allows electrons to be knocked out of their orbits and released, and electric fields in the solar cells pull these free electrons in a directional current, from which metal contacts in the solar cell can generate electricity. The more solar cells in a solar panel and the higher the quality of the solar cells, the more total electrical output the solar panel can produce. The conversion of sunlight to usable electrical energy has been the Photovoltaic Effect.

From the panel it is given to the rechargeable battery to store the current. The role of the battery stores energy when the solar cell converted and to keep the power supply at any time to load. The battery used in solar power generation system has some basic requirements, such as low self-discharge rates, long life, deep discharge ability, charging efficiency, less maintenance or maintenance-free, wide working temperature range 
and low prices. Battery used in this paper can achieve with the discharge depth of about $80 \%$ of the deep discharge maintenance-free battery. It should consider the output voltage and capacity. Its output voltage should match with the controller in the system and its capacity should insure the refrigerator working normally for some time when the system at no sunlight circumstances. The battery most commonly used is the lead acid type, long life, deep cycle batteries are preferred. A capacity to run the refrigerator for five days without sun is recommended.

In embedded unit (Figure 2) the microcontroller pic 16F887 is used.The supply is given from the battery to run the entire unit. The PIC is a family of Harvard architecture microcontrollers made by Microchip Technology, derived from the PIC1640 originally developed by General Instrument's Microelectronics Division. The name PIC initially referred to "PeripheralInterfaceController".Embedded system consists of five ports[port $\mathrm{a}$, port $\mathrm{b}$, port $\mathrm{c}$, port $\mathrm{d}$, port e]. With this system in port-a temperature sensor, in port-b LCD display, in port-c keypad and in port-d relay driver is connected. ADC was inbuilt in the controller. Figure 2 shows the embedded unit. The change in the temperature values is simultaneously displayed on the $16 * 2$ line LCD panel.LCD Display is used for displaying the status of the processing.The LCD doesn't generate light and so light is needed to read the display. Driver circuit is an electrical circuit used to power the LCD.The LCD is connected to the port $\mathrm{b}$ to display the temperature readings. A keypad consists of three buttons. The first and second buttons are used to set the hot and cold condition. The last button is used to set off the condition.The relay driver circuit is enabled certain time duration only, such enable pulse is depended by delay programming of microcontroller, here Darlington circuit has been two transistors made connection of cascade network, if input is set to the base of the first transistor, then that turns on and emitter current of that turn the other one. Hereby the circuit is closed through the coil and second transistors, now the energized coil is controlled the contractors that are changing the normally open to close and normally closed to open connection. The enabled signal is not essential after energizing that coil because the transistor collector current maintains the transistors in the saturated state continuously. The induction effect may affect the indication components and another thing, so the diode is connected across the coil which can prevent the chopping effect the inverse magnitude of magnetic field shorted across from the coil.

The LM35 series are precision integrated-circuit temperature sensors, whose output voltage is linearly proportional to the Celsius (Centigrade) temperature. The LM35 thus has an advantage over linear temperature sensors calibrated in ${ }^{\circ}$ Kelvin, as the user is not required to subtract a large constant voltage from its output to obtain the convenient Centigrade scaling. The LM35 does not require any external calibration or trimming to provide typical accuracies of $\pm 1 / 4^{\circ} \mathrm{C}$ at room temperature and $\pm 3 / 4^{\circ} \mathrm{C}$ over a full -55 to $+150^{\circ} \mathrm{C}$ temperature range. Low cost is assured by trimming and calibration at the wafer level. The LM35's low output impedance, linear output, and precise inherent calibration make interfacing to readout or control circuitry especially easy. It can be used with single power supplies, or with plus and minus supplies. The temperature sensor LM35 senses the temperature and convert it into an electrical signal which is applied to the microcontroller through the ADC. The temperature range of the sensor is $1^{\circ} \mathrm{C}$ to $255^{\circ} \mathrm{C}$. A Peltier cooler is used as a thermo-electric generator. When operated as a cooler, a voltage is applied across the device, and as a result, a difference in temperature will build up between the two sides. When operated as a generator, one side of the device is heated to a temperature greater than the other side, and as a result, a difference in voltage will build up between the two sides.

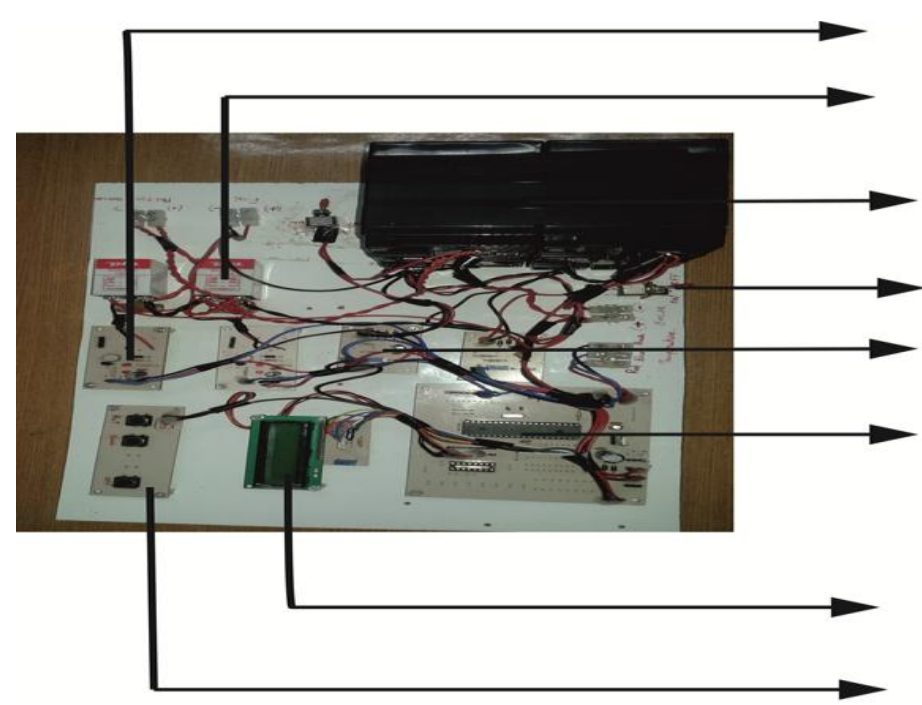

Figure. 2 Embedded units
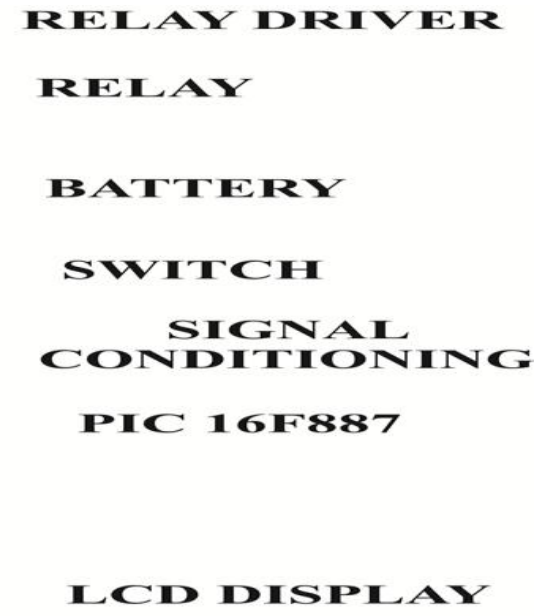

KEYPAD 
The temperature control chamber provides the user with an accurate range of ambient temperature. The chamber is shown in the figure. 3. The user can build this simple circuit and protect any issues with temperature. Moreover, it is easy to develop depends on the environment or requirement that is needed for different types of testing.

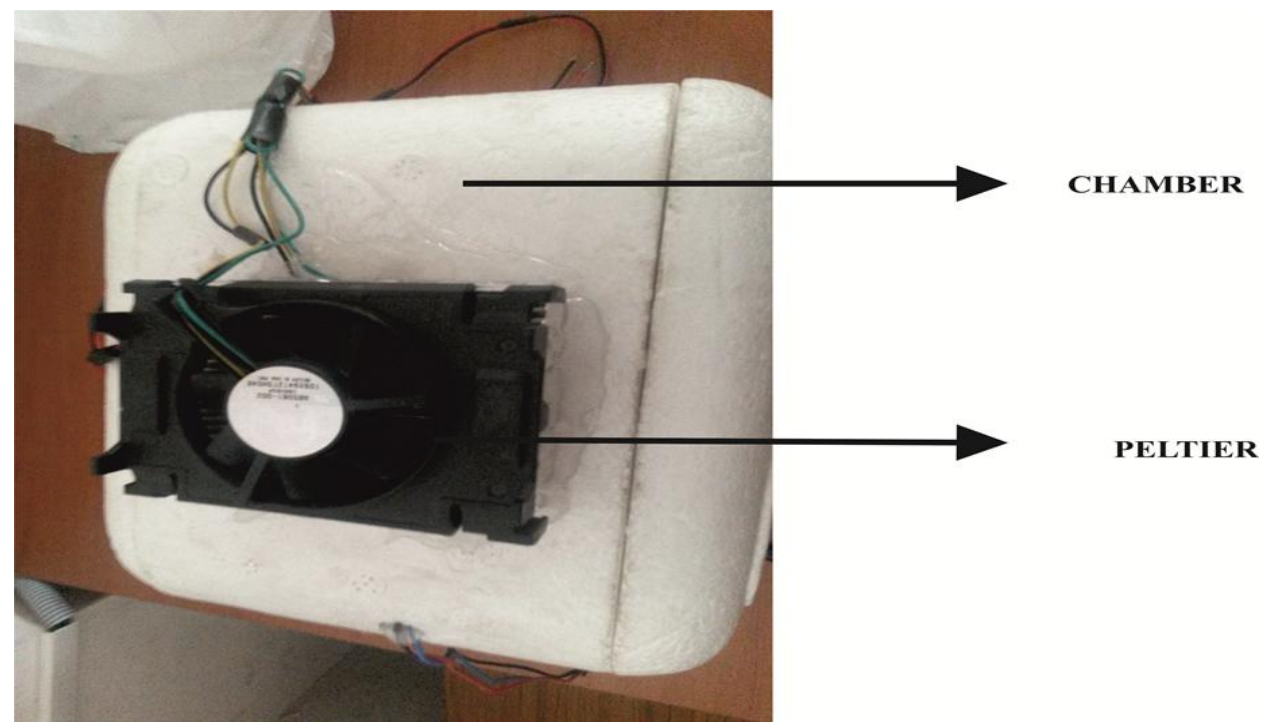

Figure.3 Temperature controlled Chamber

Also, using the variable resistors allows user to be flexible to the ambient temperature when the temperature is one of the variables in the testing. The chamber consists of hot and cold chamber for both the purposes. Table 1 shows the specifications of the temperature controlled chamber.

Table.1 Specifications of the chamber

\begin{tabular}{|l|l|}
\hline SIZE & $30^{* 30} * 30 \mathrm{~cm}$ \\
\hline SUPPLY VOLTAGE & $12 \mathrm{~V} \mathrm{DC}$ \\
\hline $\begin{array}{l}\text { POWER CONSUMPTION AT } \\
\text { COLD CONDITION }\end{array}$ & $\begin{array}{l}3.3 \mathrm{Amps} \\
40 \mathrm{Watt}\end{array}$ \\
\hline $\begin{array}{l}\text { POWER CONSUMPTION AT } \\
\text { HOT CONDITION }\end{array}$ & $\begin{array}{l}4.6 \mathrm{Amps} \\
56 \mathrm{Watt}\end{array}$ \\
\hline CAPACITY FOR COOLING & $15^{\circ} \mathrm{C}-20^{\circ} \mathrm{C}$ \\
\hline CAPACITY FOR HEATING & $60^{\circ} \mathrm{C}$ \\
\hline
\end{tabular}

\section{CONCLUSION}

In this paper, the Peltier module is used for the purpose of heating and cooling. They both heating and cooling are done in the same chamber. The minimum temperature achieved was found to be $20^{\circ} \mathrm{c}$ for cooling and the maximum temperature was $60^{\circ} \mathrm{c}$ for heating in this experiment. The cost of solar panels is high, so the size of solar panel must be replaced in order to reduce the cost.

\section{FUTURE SCOPE}

To build a real time system with,

- High efficiency for the domestic purpose.

- $\quad$ To reduce the size of the panel as much as possible. 


\section{REFERENCES}

[1] Shun Chen, Jun Zuo and Dan Xie "Design of solar power semiconductor refrigerator" in the proceedings of the $8^{\text {th }}$ World Congress on Intelligent Control and Automation July 6-9 2010, Jinan, China.

[2] Haidar. S, Isaac. I "Thermo-electric Cooling Using Peltier Cells in Cascade,"(2004).

[3] Sanjaykumar A Borikar and Uday S Wankhede "Experimental analysis of solar refrigeration system" in the proceedings of the International Conference at Purdue, July 14-17, 2008.

[4] Sort Nivas M, Vishnu Vardhan D, Raam Kumar PH, Sai Prasad, Ramya. K "Photovoltaic Driven Dual Purpose Thermo-electric Refrigerator for Rural India" in the InternationalJournal of Advancements in Research \& Technology.

[5] WHO. (1999). "Epi Equipment Test Procedures: E3". E3:Refrigerators freezers for storing vaccines and freezing ice packs, Last Update: Febuary 18, 1999, Retrieved: July 18, 2005.

[6] Raghied Mohammed Atta "Solar Water Condensation Using Thermo-electric Coolers" in the International Journal of Water Resources and Arid Environments 1 (2): 142-145, 2011.

[7] http://www.doc.ic.ac.uk/ ih/doc/lcd/

[8] http://home.iae.nl/users/pouweha/lcd/lcd.shtml 